\title{
Luxmeter Design with Proximity Sensor to Efficiently Test Light Intensity and Distance on Operation Lamp in Hospitals
}

\author{
Dika Surya Rizky Rahayu, M. Ridha Mak'ruf, and Syaifudin \\ Departement of Electromedical Engineering Poltekkes Kemenkes, Surabaya \\ Corresponding author: Dika Surya Rizky Rahayu (e-mail: dikasrahayu @gmail.com).
}

\begin{abstract}
The lighting of the operating/surgical site depends on the quality of the lighting from the overhead light source and the reflection from the curtain. Light measurement on the operating table is very necessary because it generates light that is irradiated into the cutting wound without dazzling the cutting surface so that pathological conditions can be recognized and must provide depth contrast and anatomical relationships, to ensure this proper calibration method is needed. Long-term use of medical devices can cause changes in accuracy. Therefore, the author makes a tool to measure the intensity of light which is equipped with a distance meter. The purpose of this study was to develop a measuring instrument for measuring the intensity of light in operating lamps, namely a luxmeter by making Luxmeter equipped with a TFT Display Distance Sensor. This tool uses an ultrasonic sensor HC-SR04 to measure the distance between the light source and the sensor module and the MAX44009 sensor to measure the light intensity of the operating lamp displayed on the TFT screen. Based on the module distance setting to the roll meter, the distance error value for the measurement of the Surabaya electromedical engineering workshop lamp at the $75 \mathrm{~cm}$ roll meter distance setting is $0.0127 \%$ for the $100 \mathrm{~cm}$ roll meter distance setting is $\mathbf{0 . 0 0 4 5 \%}$. The error rate of the light intensity module on the results of the measurement of light intensity on the luxmeter by setting the roll meter distance of $75 \mathrm{~cm}$ between the tool and the lamp of the electromedical engineering workshop is getting an error value of $0.082 \%$ lux and for the light intensity on the results of the measurement of light intensity on the luxmeter with a roll meter distance setting of $100 \mathrm{~cm}$ between the tool and the lamp in the electromedical engineering workshop, that is, the error value of lux is $0.055 \%$. The design of a luxmeter equipped with a proximity sensor can measure the intensity of light and the distance between the tool and the light source and can assist in the learning process with a more effective Luxmeter design that will assist electromedical engineer in testing operating lamps in hospitals to be more efficient.
\end{abstract}

INDEX TERMS HC-SR04, Luxmeter, MAX44009

\section{INTRODUCTION}

The lighting of the operating/surgical site depends on the quality of the lighting from the overhead light source and the reflection from the curtain [1]. Light is a specific part of the electromagnetic spectrum that creates a response in the human visual system, and is characterized by electromagnetic wavelengths $(\lambda)$ ranging from 380 to $780 \mathrm{~nm}$ [2]. Current illumination methods are limited by the lack of mobility, repetitive and time-lengthy adjustments, sterilization, and contamination concerns, nonoptimal illumination, inefficiencies, and time delays [3]. Illuminance meter is a light measuring instrument, this tool is used to determine the level of illumination in a room. The unit of measurement for the illuminance meter is lux or lumen $/ \mathrm{m}^{\wedge} 2$, which is the intensity of light in an area (area or space). Each type of activity/work that requires a different level of 
comfort for the human eye, from the illuminance range of 0.01 lux to 20,000 lux. SNI-03-6575-2001 regulates procedures for designing artificial lighting systems (lights) in buildings. This building is a technical guideline for design and development planning requirements and as a guide for building owners/managers to operate and maintain an artificial lighting system in order to obtain a lighting system that is in accordance with health, safety, and the provisions that apply to buildings. Testing is the entire action that includes physical examination and measurement to compare the instrument measured with the standard, or to determine the magnitude or measurement error [4]. One of the objectives of testing and calibration is to ensure the availability of medical devices that comply with service standards, quality requirements, safety, benefits, safety, and fit for use in health service facilities. one of the medical devices that must be tested and/or calibrated is an operating lamp. According to IEC standard 60601-2-41, the maximum luminance intensity for operating lamp testing is between 40,000 lux - 160,000 lux. The distance from the illuminated area to the center of the light field is 1 meter [5].

Previously made luxmeter tool by Muchamad Pamungkas in 2015 about the design and realization of light intensity measuring equipment. In his research using sensor BH1750 and can only measure the value of 65,535 1x, using a microcontroller processor ATMEGA 8 displayed on liqud crystal display $16 \times 2$ [6]. Further research by Ainul Fitroh Istiadzah in 2015 under the title lux meter based microcontroller. The sensor used is TEMT6000 which results in simulations of only up to 10,000 lux, in this study the processor is ATMEGA 8 and researchers chose to display the measurement results on liquid crystal display $2 \times 8$ [7]. Then a luxmeter was made by Akhmad Akhsin Nasrudin. namely the design and build of the luxmeter BH1750 application as a microcontroller-based water turbidity measurement tool in 2015 , but still has a weakness in the measured value due to the limitations of the design tool related to the measurement of water turbidity and is influenced by poor measurement techniques so that the maximum error value is obtained at $6.35 \%$, in this study the data was processed by ATMEGA $328 \mathrm{P}$ and the researchers chose to display the measurement data on a $2 \times 16$ liquid crystal display [8]. Herlia Agni made the arduino-based luxmeter tool equipped with a distance meter in 2017, using the GY-302 type BH1750FVI light sensor which has a drawback because the light intensity measurement is only up to 31562 lux in his research. so it still requires the development of the light sensor side, the distance sensor used is the ultrasonic PING sensor))), in this study the data was processed using ATMEGA 328 and the researcher chose to display the measurement data on liquid crystal display $2 \times 16$ [9]. Abdul Kadir made a lux meter device based on ATmega 328 in 2017, but it still has a weakness in the DFR0026 light sensor which at the time of measurement has a high error presentation at a certain distance. In this study the data was processed by ATMEGA 328 and the researcher chose displaying measurement data on the liquid crystal display nokia 5110 [10]. Made Satriya created the design and manufacture of lux meter digital based on El7900 light sensor in 2018, using El7900 light sensor which has a drawback because the measurement of light intensity of blue filter has a high error. In this study the data was processed by the R8C/13 microcontroller and the researchers chose to display the measurement data on liquid crystal display M1632 [11]. Then the research of luxmeter tools continued by Royditya Astrawinanta titled design build luxmeter equipped with arduino-based distance sensor in 2019, here researchers use MAX44009 sensor which includes light intensity sensor with readings entering the operating lamp criteria $0.045-188.000$ $\mathrm{lx}$ and distance sensor used hcsr-04 that can read distance well. The research was processed using nano arduino and displayed on liquid crystal display $16 \times 2$ [12]. Light is a specific part of the electromagnetic spectrum that creates a response in the human visual system, and is characterized by electromagnetic wavelengths $(\lambda)$ ranging from 380 to $780 \mathrm{~nm}$. [2]

From the development of the luxmeter that has been done by previous researchers as described in the paragraph above, it can be seen that, developments in terms of display on the luxmeter tool, researchers mostly choose to use LCD as a display tool. Disadvantages in the use of LCD displays, namely the limited viewing angle makes the resulting image different, the vision must be parallel in front of the monitor. Thus, the object of this research is to develop a luxmeter display display into a TFT LCD display with a tool design that makes it easier to use for testing operating lamps in accordance with effective and efficient standards, thus helping electromedics in testing operating lamps in health care facilities.

\section{MATERIALS AND METHODS}

\section{A. EXPERIMENTAL SETUP}

In this study, using the HC-SR04 distance sensor data collection at a distance of $74 \mathrm{~cm}$ and $100 \mathrm{~cm}$ as much as $6 \mathrm{x}$, the MAX4409 light sensor using a luxmeter at a distance of $74 \mathrm{~cm}$ and $100 \mathrm{~cm}$ was taken $6 \mathrm{x}$ on the operating lamp. In the workshop light, data collection was carried out by the HCSR04 distance sensor at a distance of $74 \mathrm{~cm}$ and $100 \mathrm{~cm}$ as much as 10 times, the MAX4409 light sensor using a luxmeter at a distance of $74 \mathrm{~cm}$ and $100 \mathrm{~cm}$ was taken 10 times.

1) MATERIAL AND TOOL

This study used Arduino to regulate the overall work of the tool, MAX44009 light intensity sensor to measure light intensity (lux) in operating lamp, HC-SR04 ultrasound sensor to measure distance between sensor module and operating lamp, TFT display to display sensor readings, battery for voltage supply in module and circuit, Push Button for page transfer on nextion and to start sensor reading along with holding sensor reading value, and tools used to support the workmanship of tools include multimeters, solders, cucut pliers, cut pliers, and testpen

\section{2) EXPERIMENT}

In this study, after the design was completed, syringe pump In this research, after the designed tool has been completed. 
Therefore, data retrieval is done using a luxmeter with light intensity in different operating lamps with different distances. The distances tested were $74 \mathrm{~cm}$ and $100 \mathrm{~cm}$.

\section{B. THE DIAGRAM BLOCK}

In this study, arduino microcontroller as the data control center of input and output IC in arduino will work based on the program code entered into the microcontroller IC. Input data entered on the microcontroller are MAX44009 light sensor, HC-SR04 ultrasonic distance sensor, hold button and reset button. This button is used to set the operation of the tool. The distance and light sensors will send digital data to the arduino to be processed into values in $\mathrm{cm}$ and lux. After reading, the arduino microcontroller displays the data reading to the arduino TFT. In this study, the measurement of operating lamps was carried out based on the placement of the tool module which contained a distance sensor and a light intensity sensor with a light irradiation point as shown in FIGURE 1.
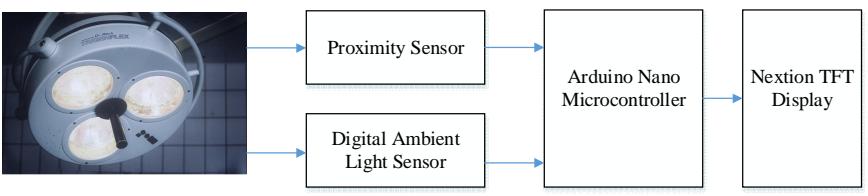

FIGURE 1. Diagram Block

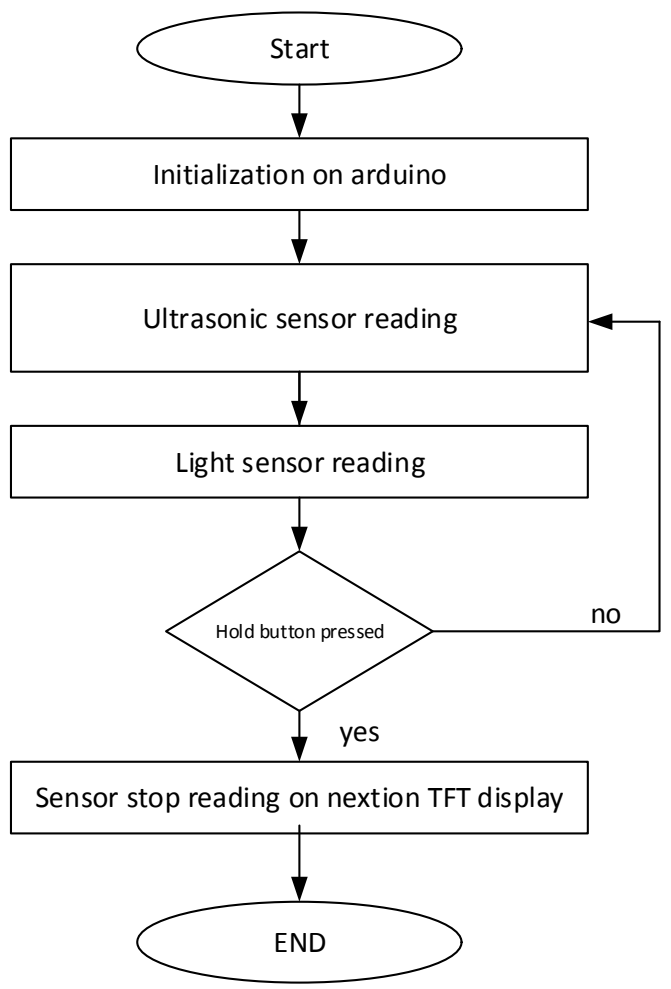

FIGURE 2. The Flowchart of Luxmeter

\section{THE FLOWCHART}

The Arduino program was built based on the flowchart as shown in FIGURE 2. When the device is turned on, the microcontroller will initialize. Then read the data from the proximity sensor displayed on the TFT. Proceed to the process of reading data from the light sensor which will be displayed on the TFT. Then press the hold button to hold the reading value during data retrieval.

\section{COMPONENT ARRANGEMENT IN TOOLS}

An important part of this research is the circuit described in FIGURE 3 (microcontroller circuit and display), This circuit is used to process light sensor data and proximity sensor data from output sensor to nextion display.

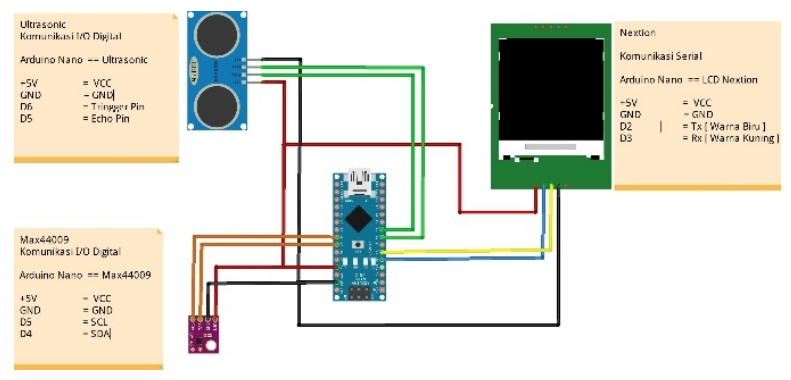

FIGURE 3. Connection of each Component

\section{RESULT}

FIGURE 4 and FIGURE 5 is the front-view image of the final task tool titled "Design Luxmeter equipped with proximity sensor displayed on TFT LCD"

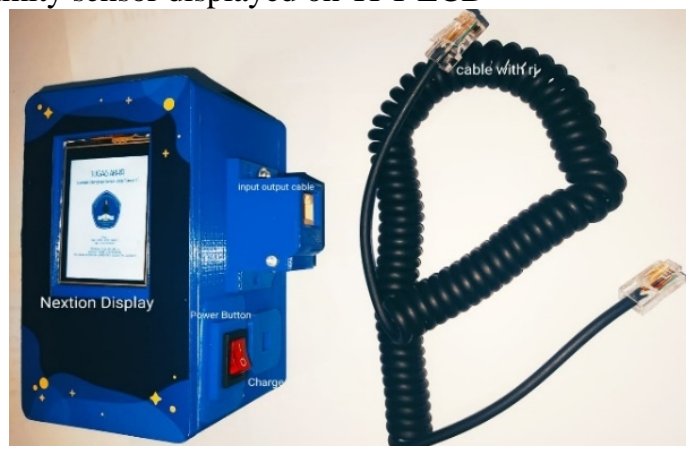

FIGURE 4. Design Module

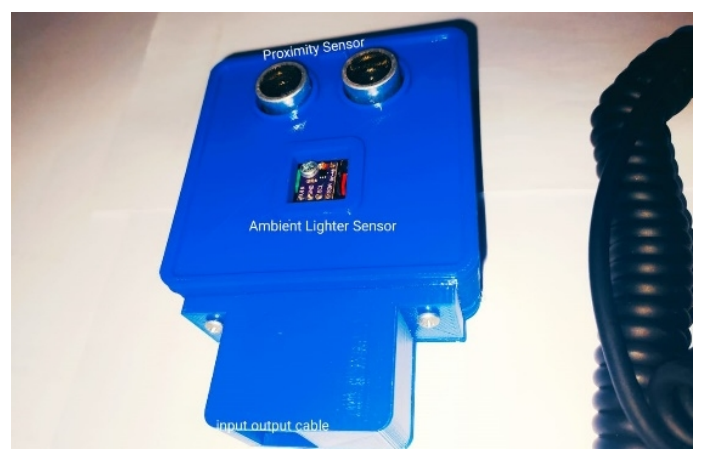

FIGURE 5. The Part of Sensor

1) DESIGN MODULE 
As in FIGURE 4. And FIGURE 5, When the design of this module is turned on, the Arduino Microcontroller as the center for controlling the input and output IC data on the Arduino will work based on the program code that is entered into the microcontroller IC. The input data that enters the microcontroller is the MAX44009 light sensor, the HC-SR04 ultrasonic distance sensor, the hold button. This button is used to set the operation of the tool. The proximity and light sensors will send digital data to Arduino to be processed into values in $\mathrm{cm}$ and lux. After reading, the Arduino microcontroller will display the data reading to the Arduino TFT.

\section{2) THE LISTING PROGRAM FOR ARDUINO}

Pseudocode: Program for digial mbient light sensor dan ultrasonic sensor

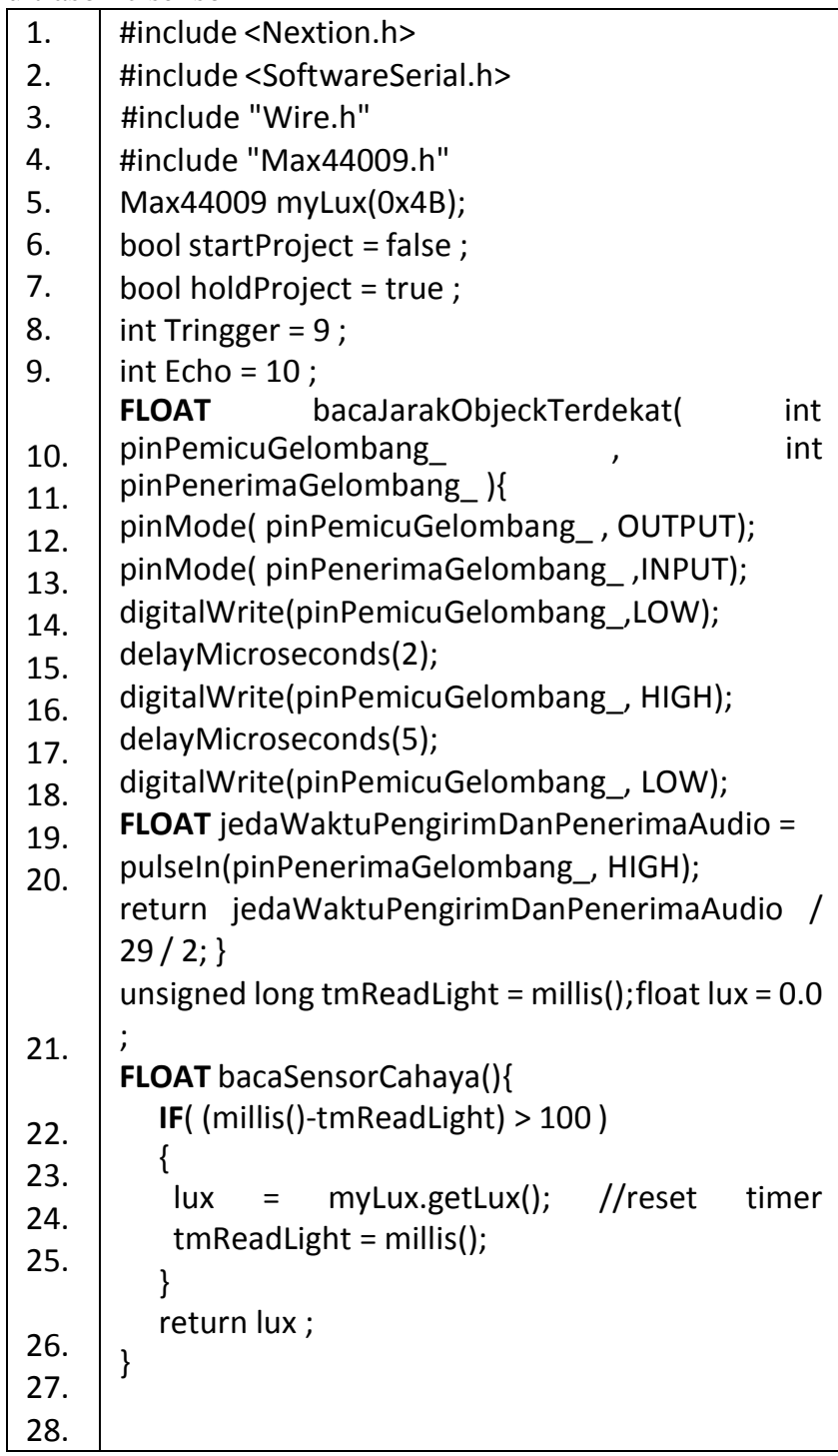

In program psendcode, there is a program for sending frequency audio signal waves then frequency audio waves will be received and then the delay in sending and receiving time will be converted into distance. There is also a program for a digital light sensor, the sensor reading starts from 0 . If the lux reading time is $>100 \mathrm{mS}$ then lux will reset the timer "lux $=$ myLux.getLux ()$;$; and will be repeated continuously "return lux ;".

\section{3) GRAPH RESULT FROM DATA DISPLAYED ON TFT}

In the result is made by measurement from workshop lamp with luxmeter standart. Before the luxmeter was tested on the lamp, the device was calibrated using konika monolta from BPFK. FIGURE 8 show the grapich from ambient light sensor and proximity sensor. The graphic from the source directly from Microsoft Excel.

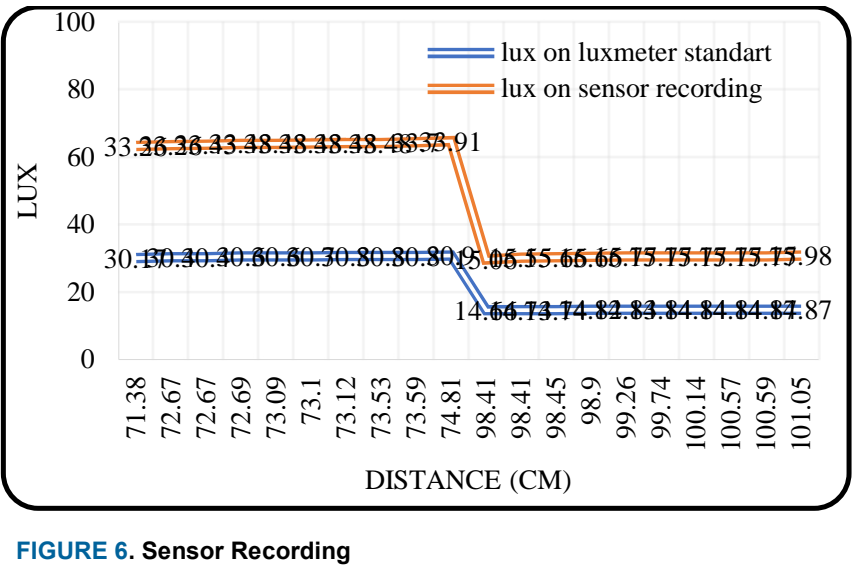

4) RESULTS OF MEASUREMENT AND TESTING PERFORMANCE OF LUXMETER BRAND AMPROBE

In testing and measurement of luxmeter performance is done to determine the performance of luxmeter. Validate the distance value shown on the nextion tft display compared to the roll meter. The error is shown in Table 1.

Table 1

The error of measurement for distance parameter between luxmeter and the luxmeter brand (amprobe luxmeter)

\begin{tabular}{c|c}
\hline \hline HC-SR04 & Error(\%) \\
\hline $74 \mathrm{~cm}$ on surgical lamp & 0,002913871 \\
$100 \mathrm{~cm}$ on surgical lamp & 0,035840066 \\
$74 \mathrm{~cm}$ on workshop university lamp & 0,012796825 \\
$100 \mathrm{~cm}$ on workshop university lamp & 0,004500161
\end{tabular}

Table 2

The error of measurement for the Lux parameter between the LUXMETER and Standard Unit (Amprobe luxmeter).

\begin{tabular}{ccc}
\hline \hline No & Subject & Error (\%) \\
\hline \multirow{3}{*}{1} & $\begin{array}{c}\text { Lux on distance } 74 \mathrm{~cm} \\
\text { workshop lamp }\end{array}$ & 0,08296513 \\
& $\begin{array}{c}\text { Lux on distance } 100 \mathrm{~cm} \\
\text { workshop lamp }\end{array}$ & 0,055626435 \\
\hline
\end{tabular}


The measurement of the light intensity value where the lux from the electromedical engineering workshop lamp is also compared in this study, between the Luxmeter design and the standard Luxmeter. The results are shown in Table 2.

\section{DISCUSSION}

In this study, there were measurements on 2 light sources, namely the GEA brand operating lamp at RSIA Putri Surabaya and the Surabaya electromedical engineering campus workshop lamp. Measurement of the two light sources includes measuring the distance from the light source with a luxmeter and measuring the intensity of light emitted by the light source. Measurements are made with the right focus of light on the luxmeter (central illumination). For distance measurement, the writer compares it with a standard roll meter tool and for measuring light intensity it is compared with a standard luxmeter tool.

Measurement of operating lamps at RSIA Putri Surabaya, in this measurement the author uses 2 distances to measure light intensity, the first distance is $74 \mathrm{~cm}$ on a standard roll meter and the ultrasonic sensor error value HC-SR04 is $0.002913871 \%$, the second distance is $100 \mathrm{~cm}$ on a standard roll meter and the ultrasonic sensor error value HC-SR04 is $0.035840066 \%$. From the measurement results for the distance parameter with a distance setting of $74 \mathrm{~cm}$ and 100 $\mathrm{cm}$, namely the GEA $15+12$ brand operating lamp still meets the standard because the lux value is still within the allowed limits. According to the standards of the directorate of medical support services and health facilities, the directorate of health efforts of the ministry of health of the republic of Indonesia in 2012, regarding the technical guidelines for operating room hospital buildings, operating lamps generate intensive light with a range from 10,000 lux to 20,000 lux, and at standard IEC 60601-2-41, the maximum luminance intensity for operating lamp testing is between 40,000 lux 160,000 lux. After the measurements were made, the results of measuring the lux value on the GEA $15+12$ brand operating lamp were within that range. After taking measurements, it was found that the average value of the data taken on the GEA $15+12$ brand operating lamp was in the specified range so that it can be concluded that the tool can still function properly. Measurement of lamps at the Surabaya electromedical engineering campus workshop, in this measurement the author uses 2 distances to measure light intensity, the first distance is $74 \mathrm{~cm}$ on a standard roll meter and the ultrasonic sensor error value HC-SR04 is $0.012796825 \%$, the second distance which is $100 \mathrm{~cm}$ on a standard roll meter and the ultrasonic sensor error value of HC-SR04 is $0.004500161 \%$. Then the central light intensity measurement was carried out at the Surabaya electromedical engineering campus workshop lamp with 2 different distances, the first measurement used a measuring distance of $74 \mathrm{~cm}$ and the results of the MAX4009 type (GY-49) digital light sensor error were $0.08296513 \%$, the measurement of light intensity at a distance of $100 \mathrm{~cm}$, the error result of the digital light sensor MAX4009 type (GY-
49 ) is $0.055626435 \%$. From the results of the measurement of the lamp at the Surabaya electromedical engineering c ampus workshop, it can be seen in the results of the measurement graph that the farther the measuring distance between the light source and the tool, the smaller the light intensity value obtained. Therefore, this luxmeter equipped with a TFT display distance sensor can function properly.

However, to ensure the correctness of the measurement test that has been conveyed above, the next stage must still be carried out, namely comparing the luxmeter module with a luxmeter that has been properly calibrated so that it can be seen that the operating lamp that has been measured is suitable for use or not. Errors in the tool can be caused by human error, the life time of the operating lamp can also affect the measurement results.

Therefore, this luxmeter equipped with a TFT display distance sensor can assist in measuring light intensity more effectively with the automatic reading of the distance sensor without the need to use a roll meter again, the output results displayed on Nextion can also help readings more effectively and with a design a simpler tool such as a luxmeter on the market so that the use of a luxmeter can be more efficient.

\section{CONCLUSION}

This research has succeeded in making a design luxmeter to measure the calibration distance between the light source and the central illumination and measure the light intensity at the central illumination using a digital light intensity sensor using arduino nano for data processor and nextion TFT display to display sensor readings in real time. time is equipped with a hold button to hold the sensor reading value. With an average error of $74 \mathrm{~cm}$ distance testing of $0.007855348 \%$, an average of $100 \mathrm{~cm}$ distance testing error of $0.0201701135 \%$ and testing on light intensity getting error values of $0.08296513 \%$ and $0.055626435 \%$. The error results are influenced by different human readings (human error), untraceable comparison tools, the lifetime of the light source. Developments that can be done from this research are using the latest light and distance sensors and having high accuracy and measuring range values, comparing the results of the luxmeter module with the original calibrated and usable luxmeter, adding an easier data retrieval system using an application on a cellphone. So that it can be easier for the user, to upgrade the tool by adding the features of Kelvin, room temperature and humidity for testing more modern operating lamps.

\section{REFERENCES}

[1] M. Dr. Supriyantoro, Sp.P, Bangunan dan sarana rumah sakit, 2012th ed. Indonesia: Kementrian Kesehetan RI, 2012.

[2] Prof. Ir. K.C.A.M Luyben, Surgical light, ISBN/EAN:, vol. 20, no. 3. Nederland: Prof. dr. J. Dankelman, 2017.

[3] J. Curlin and C. K. Herman, "Current State of 
Surgical Lighting,” Surg. J., vol. 06, no. 02, pp. e87e97, 2020, doi: 10.1055/s-0040-1710529.

[4] P. Sadeghian, C. Wang, C. Duwig, and S. Sadrizadeh, "Impact of surgical lamp design on the risk of surgical site infections in operating rooms with mixing and unidirectional airflow ventilation: A numerical study," J. Build. Eng., vol. 31, no. March, p. 101423, 2020, doi: 10.1016/j.jobe.2020.101423.

[5] A. Huskey, "International Standard," in 61010-1 () Iec:2001, First edit., vol. 01, no. 02, SWITZERLAND: IEC, 2003, pp. 2-41.

[6] M. Pamungkas, H. Hafiddudin, and Y. S. Rohmah, "Perancangan dan Realisasi Alat Pengukur Intensitas Cahaya," Elkomika J. Tek. Energi Elektr. Tek. Telekomun. Tek. Elektron., vol. 3, no. 2, p. 13, 2015, doi: 10.26760/elkomika.v3i2.120.

[7] P. C. N. Ainul Fitroh Istiadzah, Andjar Pudji, "Lux meter berbasis mikrokontroler," J. Teknokes, vol. 2, no. 3, pp. 1-6, 2015.

[8] D. Akhmad Akhsin Nasrudin, "Rancang Bangun Aplikasi Lux Meter BH1750 sebagai Alat Ukur Kekeruhan Air Berbasis Mikrokontroller Akhmad Akhsin Nasrudin , Dzulkiflih," J. Inov. Fis. Indones., vol. 04, no. 03, pp. 89-94, 2015.

[9] P. C. N. Herlia Agni Agria Marasyta, Hj. Andjar Pudji, "Radiance Intensity, Water Turbidity, Lightsensor BH1750.," J. Teknokes, vol. 04, no. 02, pp. 1-11, 2017.

[10] A. K. Jailani, P. C. Nugraha, and T. Hamzah, "Lux Meter Digital Berbasis ATmega 328," J. Teknokes, vol. 04, no. 05, pp. 1-6, 2017.

[11] I. M. S. Wibawa and I. K. Putra, "Perancangan Dan Pembuatan Lux Meter Digital Berbasis Sensor Cahaya El7900," J. Ilmu Komput., vol. 11, no. 1, p. 45, 2018, doi: 10.24843/jik.2018.v11.i01.p06.

[12] R. Astrawinanta and T. Rahmawati, "Rancang Bangun Luxmeter Dilengkapi Sensor Jarak Berbasis Arduino," J. Teknokes, vol. 10, no. 05 ISSN: 26849518, pp. 147-151, 2019.

Attachment:

a. Schematic+Board:

https://drive.google.com/drive/u/0/folders/1LktesiSUccqdbea4 GhlWUNUIO36uagCZ

b. Listing Program :

https://drive.google.com/drive/u/0/folders/1PRm5y0HKqC0Jg VzDgBhHkmQbhb2xikLO 